\title{
CONFLITOS INDÍGENAS NA REGIÃO NORTE DO ESTADO DO RS
}

\author{
Darci Emiliano ${ }^{1}$ \\ Vilmar Alves Pereira ${ }^{2}$
}

Resumo: Este artigo tem o objetivo de refletir sobre os conflitos indígenas da região Norte do Rio Grande do Sul, destacando a importância da mediação como possível alternativa e solução. Diante disso, compreende-se a impossibilidade da formação de consenso num contexto de ameaça ou perda de direitos que envolvem perda de identidade, de cultura, de propriedade, enfim questões que estão gerando uma tensão no norte do Rio Grande do Sul, entre indígenas e agricultores. Assim, este estudo, associado à vivência de um indígena e estudante, oriundo dessa região, faz uma revisão bibliográfica acerca do assunto. Ele concluiu que os grupos envolvidos no conflito de terra (indígenas e não-indígenas) precisam ter preservadas suas concepções e visões sobre o mundo. Defende a premissa que toda e qualquer mediação, seja por meio de políticas públicas ou entidades representativas, ou pela Educação Ambiental Crítica, necessita atentar para as singularidades e individualidades, ao desenvolver ações junto aos envolvidos. É preciso construir um diálogo que reproduza, de fato, uma compreensão objetiva sobre as relações sociais, culturais e históricas, presentes nos conflitos de terra, as quais são mais relevantes que o aspecto econômico, a posse, e a propriedade.

Palavras-chave: Agricultores; Conflitos de Terra; Indígenas

${ }^{1}$ Instituto Federal de Ciência e Tecnologia do Rio Grande do Sul - IFRS - Campus Sertão E-mail-darci.emiliano@sertao.ifrs.edu.br.

${ }^{2}$ Associação Rio Grandina de Umbanda e Religiões de Matriz Africana - ARUTEMA, RS.

E-mail: vilmar1972@gmail.com. 
Abstract: This article aims to reflect on indigenous conflicts in the northern region Norte of Rio Grande do Sul, highlighting the importance of mediation as a possible alternative and solution. Thus, it is understood that it is impossible to form a consensus when there is a threat or loss of rights involving loss of identity, culture, property, in short, issues that are generating tension in the north of Rio Grande do Sul, between indigenous and farmers. This is a literature review study associated with the experience of an indigenous and student from the region. It was concluded that the groups involved in the land conflict (indigenous and non-indigenous) must have preserved their conceptions and views about the world. Therefore, any and all mediation, whether through public policies or representative entities or through Critical Environmental Education, need to pay attention to the singularities and individualities, when developing actions to work with those involved, building a dialogue that actually reproduces an understanding of the relationships social, cultural and historical factors that are present in the land conflict, more relevant than the economic aspect, tenure, and property.

Keywords: Farmers; Earth Conflicts; Indigenous People.

\section{Introdução}

Estes são tempos marcados por injustiças socioambientais causadas pela falta de demarcação de terras para os povos indígenas, desmatamentos, queimadas, usos de agrotóxicos e pela tentativa de aprovação da Medida Provisória 910, reconhecida como a MP do incentivo e permissividade à grilagem, nas terras dos povos da floresta, em especial os indígenas. Elas resultam de um amplo conjunto de fatores, associado ao modo de produção capitalista, que prioriza a economia em detrimento da vida. No caso dos povos tradicionais indígenas, no Brasil, cotidianamente acentuam-se novas faces da perspectiva do opressor (manifestada pela gestão do governo Bolsonaro), que busca mitigar e, muitas vezes, extinguir suas vidas. Mesmo depois de tantas violências ainda vemos, por parte dos governantes, aculturações forçadas visando legitimar suas decisões de explorar as terras e as riquezas indígenas. Assim, cresce entre as populações indígenas, o sentimento de serem arrancadas e expropriadas do seu próprio meio fazendo-os clamar por justiça ambiental (PEREIRA, 2020).

Este artigo tem o objetivo de refletir sobre os conflitos indígenas da região Norte do Rio Grande do Sul, sob o viés da importância da mediação como possível solução. A relevância do tema consiste na compreensão de que os indígenas possuem uma história de exclusão e de expropriação social, cultural e econômica (TEDESCO; KUJAWA, 2013).

Mediante esse grave quadro e buscando mudar esta realidade, os indígenas vêm reivindicando seus direitos constitucionais para assegurar sua cultura, manter sua identidade e conquistar seu espaço territorial. Realizam esse movimento através de reuniões com as lideranças e de reivindicações junto à FUNAI, com sede em Passo Fundo-RS, amparados na Constituição Federal de 1988. Na região norte do Rio Grande do Sul, essa questão é o 
cerne dos conflitos envolvendo indígenas e não indígenas, em relação à conquista da terra (TEDESCO; KUJAWA, 2013).

$O$ assunto demanda uma abordagem interdisciplinar, por se tratar de questões situadas para além de interpretações jurídicas estabelecidas por legislações de corte positivista, que não conseguem abranger, com propriedade, os problemas e as nuances de cada contexto. Nesse sentido, busca-se um olhar mais abrangente que envolva estudos dos campos da Sociologia, da Antropologia, da História, da Saúde e da Educação Ambiental. Essas áreas possuem um conhecimento organizado e ordenado que respeita as identidades de ambos os grupos envolvidos e suas relações com o espaço onde vivem ou buscam se estabelecer, de sorte que legislações e decretos não conseguem acolher as especificidades da população indígena. Apenas para ilustrar, até a recente década de 1980, a legislação de corte positivista definia que um indígena necessitava de tutela, pois não era considerado um sujeito racional.

Por essa razão, compreende-se a dificuldade da formação de um consenso, quando existe ameaça ou perda de direitos que envolvem perda de identidade, de cultura, de propriedade, enfim questões que estão gerando uma tensão explosiva entre indígenas e agricultores, no norte do Rio Grande do Sul. A referida tensão passa, entre outros aspectos, pelo modo usado, no decorrer dos anos, pelos produtores que foram adentrando às terras indígenas e, aos poucos, apropriando-se delas, inclusive ocasionando agressões físicas com uso de arma de fogo e de arma branca. Muitos começaram com sistema de arrendamento, outros usaram de força e invadiram as terras delas expulsando muitos indígenas. O que se vê, com muita frequência, na região norte do Rio Grande do Sul, em áreas de beira da estrada, são as barracas das muitas famílias indígenas que perderam suas terras.

Cabe inferir, ainda, que se trata de questões conflituosas para ambos os sujeitos, gerando idealizações negativas e positivas que ficam à mercê das decisões das esferas jurídica e política, em âmbito Federal e Estadual, pois são conflitos de direitos e de luta pela legitimidade da propriedade da terra e das especificidades do debate em torno do direito indígena ao solo (TEDESCO; KUJAWA, 2013). As referidas idealizações dizem respeito ao sonho, dos indígenas, muitas vezes frustrado, de terem suas terras. Para o indígena Kaingang, tudo vem da terra, por isso a sua frustração e a dificuldade da manutenção da vida quando não existe o direito da propriedade da terra.

Desse modo, neste artigo apresenta-se, primeiramente, o contexto histórico indigenista, abordando-se a terra dos Kaingangs. Posteriormente, passa-se às questões que geram os conflitos na região Norte do Rio Grande do Sul e, por fim, conclui-se abordando a importância da mediação para transformar as tensões que refletem uma distribuição desigual dos direitos entre os indígenas e os não-indígenas. 


\section{Os indígenas no Brasil, no Rio Grande do Sul e no Norte Gaúcho}

Os primeiros Projetos Protecionistas do Estado, direcionados aos indígenas, foram o Serviço de Proteção aos Índios (SPI), já extinto e, a partir de 1967, a Fundação Nacional do Índio (FUNAl). Essas instituições têm, como objetivo, efetivar a integração dos indígenas à cultura dos não-indígenas, procurando transformá-los em mão de obra assalariada. A seu turno, a FUNAI tem falhado nos seus propósitos por opções e usos políticos em favor de políticas de governo. Isso faz com que, atualmente, esteja em descrédito pela maioria das comunidades indígenas dessa região. Contudo, é possível dizer que os indígenas resistem a uma integração cultural nacional, já que procuram ressignificar seu modo de vida, firmando sua identidade e sua cultura, bem como assegurar seus direitos no que diz respeito ao seu espaço (ALMEIDA; PICOLOTTO; SPINELLI, 2017), razão pela qual

[...] o Movimento Indígena no Brasil apresenta a consciência de luta dos povos indígenas por meio das intermediações das Assembleias Indígenas realizadas, a partir da década de 1970, por organizações como a União das Nações Indígenas-UNI, o Conselho Indigenista Missionário - CIMI, Instituto Socioambiental - ISA, entre outras. Grandes encontros foram realizados entre povos de diferentes etnias nas décadas de 1970 e 1980, momentos em que elaboraram pautas reivindicando no processo Constituinte a intervenção do Estado para reparação dos danos causados em nome do desenvolvimento nacional (ALMEIDA; PICOLOTTO; SPINELLI, 2017, p. 74)

Desde a colonização, os indígenas sofreram o desprezo por sua cultura, seu patrimônio e sua história. Além disso, ainda lhes foram tiradas, pelos colonizadores, a terra e as matas. No caso em estudo, pelos agricultores familiares, donos de terras nessa região do agronegócio, com plantio de soja e milho e uso deliberado de agrotóxicos. Atualmente, buscam resgatar e garantir seus direitos, tornando sua luta visível à sociedade.

A colonização do Rio Grande do Sul (RS), especialmente na sua região Norte, nos séculos XIX e XX, foi cenário de contradições políticas que até hoje afetam as relações entre indígenas e agricultores familiares. Tais contradições foram consequências das políticas de segregação/exclusão territorial indigenista que promoveram direitos de ocupação e de propriedade sobre as mesmas áreas a indígenas e agricultores em diferentes momentos. Por conta da iniciativa do Estado, com a demarcação dos toldos (reservas) no norte gaúcho, em que as terras indígenas foram demarcadas (entre 1910-1918) e anos mais tarde (1940-1960) foram vendidas a agricultores (ALMEIDA; PICOLOTTO; SPINELLI, 2017, p. 86) 
Os historiadores Kujawa e Tedesco (2014) explicam que, com a Proclamação da República, no Rio Grande do Sul, ocorreu a intensificação da política de garantia das áreas indígenas motivada pelos ideais positivistas de constituir uma proteção fraternal aos silvícolas. Simultaneamente, efetivou-se o projeto de colonização das regiões florestais através do fracionamento de propriedades privadas e da venda de terras devolutas consideradas propriedade do Estado, passando, as antigas aldeias a serem demarcadas como toldos. Ainda relatam Kujawa e Tedesco (2014, p. 70) que:

No século XIX, a ocupação se intensifica com as políticas de motivação e atração de imigrantes açorianos, alemães e italianos, os quais ocupam a região do Vale do rio dos Sinos e da Serra. A região norte do estado, especificamente a da Encosta da Serra e do Alto Uruguai, tem a colonização intensificada após a Proclamação da República nas primeiras décadas do século $X X$, fruto de um movimento de migração dos descendentes dos primeiros imigrantes italianos e da política de colonização desenvolvida pelo governo do referido estado. Obviamente que a tardia colonização não significa a existência de um vazio populacional, uma vez que a região em tela tinha uma intensa ocupação indígena, principalmente kaingang, que vivia nestas matas e estendia o seu habitat para o oeste de Santa Catarina, Paraná atingindo o atual estado de São Paulo.

Com a expansão da colonização e a nova configuração do espaço, definiu-se a ocupação dos espaços indígenas e dos colonos, evidenciando-se três momentos históricos sobre esta questão da delimitação:

[...] nas primeiras décadas do século XX, quando se consolida a políticas de aldeamento e se desenvolve o projeto de colonização; a segunda, entre as décadas de 1940-60, quando se reduz as áreas indígenas demarcadas destinando-as para a criação de reservas florestais e para loteamento vendido para agricultores e, por fim, após a Constituição de 1988 e a reconfiguração do direito indígena sobre as terras tradicionalmente ocupadas, quando, nessa última ocorre a retomada das terras indígenas historicamente demarcadas no início do século XX (KUJAWA; TEDESCO, 2014, p. 70)

Ao norte do Rio Grande do Sul, os conflitos surgiram no período de 1970 e 1990, quando os povos indígenas começaram a ter reconhecimento jurídico. Eles se mobilizaram para buscar seus direitos sobre as tradicionais áreas de ocupação tradicional, sobre as quais, muitos agricultores já possuíam títulos de propriedade. Este cenário acabou por criar o conflito entre indígenas e não indígenas (ALMEIDA; PICOLOTTO; SPINELLI, 2017). Cabe dizer que os 
conflitos se acentuaram no momento em que não havia mediação do Estado. Quando ela ocorreu, apenas contribuiu para que os agricultores fossem indenizados pelas terras ocupadas. Em contrapartida, os indígenas não recuaram na busca de seus direitos pela terra, forçando o Estado a tomar medidas concretas. A propósito, mencionam Kujawa e Tedesco (2014, p. 79) que:

Após longo período de debates e tensões sociais foram restituídos os limites originários das 11 áreas demarcadas no início do século XX, restando um imenso problema econômico para o Estado para indenizar o conjunto de agricultores e, obviamente, um custo muito grande para as famílias que compraram as terras do Estado e, após algumas décadas, viram-se obrigadas a se retirarem.

É inegável a incompreensão da sociedade, de forma geral, sobre as questões indígenas, o que revela a importância dos movimentos indígenas que buscam minimizar os sentimentos de perdas, irrecuperáveis, por abrangerem identidade, cultura, respeito, tradição e espaço territorial.

Foram décadas de danos, que atingiram várias gerações indígenas, sendo necessário criar ações que oportunizem a ressignificação de sua história. Procedente, dizer, que exatamente neste sentido, os indígenas buscam, na educação escolar, um meio para revelar sua visão e seu sentimento sobre o que de fato ocorreu em sua trajetória, suas perdas e suas conquistas, as quais não podem ser interpretadas apenas pelos não indígenas (KUJAWA; TEDESCO, 2014)

Conforme Bello (2005), é possível fazer referência a iniciativas que lutam por efetivar a educação indígena, objetivando corrigir aquilo que o período de colonização gerou no Brasil - a desigualdade - ao negar, não só aos indígenas, mas aos mais pobres e aos negros, o acesso à educação, contribuindo para o agravamento da exclusão e da discriminação social desses grupos.

Comenta Bello (2005, p. 41-42) que:

Como não poderia ser diferente, a realidade da educação no Brasil reflete exatamente a mesma situação de dominação socioeconômica de uma pequena elite, que concentra praticamente todo o poder econômico do país em suas mãos, ao passo que a grande maioria da população se encontra à margem das condições minimamente aceitáveis de acesso à educação básica e superior. 
Mesmo o Brasil tendo passado por mudanças estruturais na Educação, nos governos Lula e Dilma, na atual conjuntura, na educação básica, o ensino público ainda apresenta limitações quando comparado ao ensino particular. Isso é compreensível se tomarmos por referência as desigualdades aqui existentes, a concentração de riqueza nas mãos de poucos privilegiados e o grande número de excluídos e marginalizados, historicamente, pelo sistema capitalista aqui vigente. Uma das decorrências desse processo é a grande dificuldade de os estudantes de origem popular ingressarem em cursos de nível superior. Ademais, o ensino público há muito não consegue atender à demanda brasileira. Os déficits abrangem, tanto os recursos humanos como a falta de investimentos em infraestrutura. Na concepção de Bello (2005, p. 42):

(i) o Brasil continua com uma elevada taxa de analfabetismo; (ii) grande parte dos estudantes da rede pública não conclui o ensino médio (e, por vezes, o fundamental), assim não recebendo condicionamento para pleitear bons empregos e sequer ter acesso à cultura; e (iii) dentre os poucos e obstinados estudantes que os concluem tais ciclos, certamente são ínfimos os que reúnem uma bagagem de aprendizado que Ihes permita concorrer, em pé de igualdade, com estudantes de escolas particulares em concursos de vestibular. Em suma, é pífia a quantidade de estudantes da rede pública de ensino que consegue ingressar no ensino universitário público e, menos ainda, no particular.

O fato é que, no Brasil, em pleno século XXI, os indivíduos ainda são avaliados em relação à sua cor, sua etnia e seu sexo, elementos determinantes para obter oportunidades na sociedade. Existem dados referentes às desigualdades e discriminações em diferentes áreas e em diversos países (MOEHLECK, 2002).

Nesse sentido, as ações afirmativas, denominadas de reserva de vagas, política de cotas e ação compensatória, buscam equilibrar as distâncias entre dois polos: os que possuem condições econômicas e sociais de ingressar na educação e no mercado de trabalho e aqueles que não possuem tais condições, devido a décadas de invisibilidade para o Estado e a sociedade, como é o caso dos índios no Brasil (MOEHLECK, 2002).

Dentre as iniciativas, cabe destaque a Universidade Estadual do Rio de Janeiro, pioneira na efetivação de ações afirmativas para negros no ensino superior, em 2003. Os indígenas foram contemplados com três vagas suplementares permanentes no estado do Paraná, com base na Lei n. 13.134/2001. Em 2001, uma Universidade do Estado do Mato Grosso (UNEMAT) criou o primeiro curso de Licenciatura Intercultural, visando suprir as demandas por professores nas escolas indígenas que apresentavam a maior taxa de evasão (LOBATO; BENEDETTI, 2012). 
Nos últimos anos, em especial nos Governos Lula e Dilma, além da Lei de Reserva de vagas, $\mathrm{n}$ - 12.711/2012, foram criados, em Universidades Públicas, inúmeros processos seletivos específicos para indígenas e quilombolas. Este foi o caso da Universidade Federal de Rio Grande-FURG, com processos ao nível de Graduação (em todos os cursos) e Pós-Graduação (nas áreas humanas, em especial em Educação e Educação Ambiental).

Compreende-se que:

Os saberes das comunidades tradicionais devem transpassar a universidade, atingindo o ensino, a pesquisa e a extensão. Afinal a educação não é um bem individual, que visa ao desenvolvimento de competências individuais, mas sim um bem coletivo, objetivando a construção da cidadania. Tanto indígenas quanto negros enfrentam resistências, seja dos próprios movimentos sociais ou de suas comunidades, quando da reivindicação de acesso à universidade, sobretudo via políticas de discriminação positiva (LOBATO; BENEDETTI, 2012, p. 88)

Coelho (2018) comenta que, no Brasil, refletir sobre as relações entre indígenas e brancos não se constitui tarefa simples, pois existem povos indígenas que possuem mais de quinhentos anos de contato com a sociedade brasileira e povos que estão em contato há cerca de três décadas apenas. Essas diferenças têm implicações no que se refere às políticas públicas destinadas a esses povos e ao próprio diálogo que é possível estabelecer com eles. As retóricas de respeito à diversidade continuam a ser elaboradas com base em uma concepção genérica de índio, produzida à revelia desses povos, desconsiderando qualquer diagnóstico ou informação já existentes sobre eles.

Assim, entende-se que a educação é um fator preponderante para a mediação de conflitos entre indígenas e não indígenas. A partir dela, será possível construir uma ponte para o diálogo de qualquer tema, gerando a compreensão dos envolvidos sobre as questões de cada um e de todos.

A mediação desses conflitos não pode ocorrer na perspectiva das pedagogias diretivas, bancárias e tradicionais. Como considera Freire (2011) as "classes dominadas" precisam de uma educação que thes propicie perceber as injustiças sociais, de forma crítica. É nesse horizonte que emergem a necessidade de uma mediação dialógica e, portanto, crítica, que permita um processo de conscientização sobre os motivos que levaram tantos indígenas a perderem suas terras. 


\section{Os Kaigang e as questões que demandam mediação}

Conforme Tedesco (2010), os povos indígenas não conheciam a propriedade privada da terra nos moldes capitalistas. Para eles, habitar a terra era habitar sua morada onde o que possuíam era somente fruto do próprio trabalho. Já, no contexto dos processos de dominação, faz-se a distinção entre propriedade e posse, "considerando que o primeiro termo se estabelece relacionado ao sentido da terra enquanto mercadoria, ou valor de troca, enquanto os indígenas dão, a sua produção, um valor de uso" (TEDESCO, 2010, p. 16).

Tradicionalmente, a terra Kaingang é de ocupação coletiva. No acesso a terra, as relações de parentesco cumpriam um papel decisivo organizando a forma do trabalho e da apropriação dos produtos dele originados. Os Kaingang estavam divididos em grupos aliados de irmãos e cunhados sob a chefia de um determinado põ'i, hoje traduzido por cacique. A terra era ocupada por esse grupo e se houvesse uma dissidência irreconciliável os dissidentes liderados por um novo chefe procuravam um lugar mais afastado, dentro da terra conhecida, para fazer sua aldeia (TEDESCO, 2010, p. 17).

Conforme Emiliano (2015), o Kaingang, em seu modo de ser e nas suas relações humanidade-natureza, vive para manter a biodiversidade. Este povo é da floresta, e não quer abandonar sua forma tradicional de sustentabilidade, utilizando essas terras para subsistência e não com o objetivo de ganância (EMILIANO, 2015, p. 33-34).

Percebem-se, assim, nesse modo de vida, fatores econômicos, políticos, culturais e sociais que ensejam reflexões, pois como dizem Silva et al. (2009, p.13):

Os conhecimentos tradicionais levantam questões sobre muitas noções fundamentais. As comunidades Kaingang locais não podem mais ser vistas como receptoras passivas da ajuda ao desenvolvimento. Elas possuem rico acervo de conhecimentos específicos sobre o meio natural, assim como visão própria da forma como se deve efetuar sua gestão, preservados principalmente na memória dos velhos. 
As terras atuais dos Kaingang foram demarcadas, no sul do Brasil, na sua maioria entre os anos de 1900 e 1920, tendo por base o módulo colonial (embora, no Rio Grande do Sul, o Estado tenha deixado florestas protetoras que puderam continuar sendo ocupadas pelos índios até praticamente a década de 1940, quando a escassez de terras agriculturáveis jogou a colonização sobre as últimas "reservas de mato" e sobre as terras indígenas já demarcadas) (TEDESCO, 2010, p. 19).

A partir de 2000 , com a demanda de produtos agrícolas pelo mercado internacional, iniciaram-se novas pressões sobre as terras indígenas. Nesse movimento, diversas terras foram recuperadas. No entanto, as pressões não pararam e, amparadas no direito constitucional, estão voltando ao mercado por meio da prática de arrendamento em parcerias feitas entre indígenas e particulares. Essa prática acontece, tanto individualmente, através de parcerias entre alguns indígenas, quanto através de "cooperativas indígenas", o que transformou as terras indígenas em bens de mercado (TEDESCO, 2010, p. 22).

Esse mecanismo tem impedido a muitas famílias indígenas, o acesso à sua terra ancestral, transformando as aldeias em dormitórios e jogando a população nas piores e mais desprotegidas formas de trabalho, tais como carregamento de aves, corte de erva mate, colheita de maçã e de uva. Os homens passam semanas trabalhando fora da área para poder sustentar as famílias que ficam na terra indígena. Fica evidente que há uma "ausência do Estado" por falta de uma política que alie a demarcação das terras com a gestão do território como garantia de acesso à terra de plantação de subsistência, para todo cidadão indígena (TEDESCO, 2010, p. 22-23).

Por causa da demanda por terras, as ocorrências de transferências de famílias indígenas de uma área para outra estão aumentando nas populações indígenas do sul. Tidas como "parte de cultura", essas práticas vêm se constituindo numa forma de concentração de terra e renda dentro dos territórios indígenas, uma vez que as famílias transferidas são expropriadas da posse de sua terra de ocupação tradicional (TEDESCO, 2010).

Trata-se de um rito sumário de deportação, com frequência, acompanhado de práticas de violência contra a pessoa deportada e seus familiares e a destruição (e o roubo) de parte dos seus bens. Não há direito de defesa ou contestação dos motivos alegados para a transferência. As mudanças que vêm se processando, no interior das terras indígenas, antes de serem uma questão moral, constituem-se numa questão econômica e política (TEDESCO, 2010). E continua o mesmo autor:

Cada vez mais a política interna nas terras indígenas, vem reproduzindo a estrutura de classes que impedem ao indivíduo indígena gozar do usufruto exclusivo que lhe assegura a 
Constituição. As terras recentemente reavidas acabam voltando ao sistema de arrendamento, por falta de um trabalho conjunto da agência estatal de assistência que organize a gestão do território e garanta a todos o acesso à terra, como direito de cada cidadão indígena". (TEDESCO, 2010, p. 25).

Nesse sentido, é preciso compreender que o diálogo com os povos indígenas, pode viabilizar seus saberes e concepções de mundo, de sociedade e de economia, e abrir inéditas possibilidades, contribuindo para 0 enfrentamento de velhos e novos problemas que atingem a todos, indígenas e não-indígenas (BRAND; FERREIRA, 2014).

A luta pela terra tem um sujeito definido pela sua exclusão das políticas públicas e da possibilidade de aquisição da propriedade privada da terra, bem como das condições objetivas e subjetivas de existência e cidadania social e política. Esse contexto envolve o reconhecimento público e identitário, a contemplação em políticas públicas e políticas fundiárias de garantias de remuneração do trabalho incorporado nas mercadorias agrícolas (TEDESCO; VANIN, 2013)

Souza Filho (2010) explica que o direito à terra, entendida como o espaço de vida e liberdade de um grupo humano, é a reivindicação fundamental dos povos indígenas brasileiros e latino-americanos. Por esse motivo, a questão da territorialidade assume extrema relevância, pois se trata da própria sobrevivência dos povos que, sem o seu território, sentem-se ameaçados de perder suas referências culturais, sem as quais, um povo deixa de ser povo. "Esta afirmação é válida para todos os povos exatamente porque o conceito de povo está ligado a relações culturais que por sua vez se interdependem com o meio ambiente" (SOUZA FILHO, 2010, p. 119-121).

É fato que, no Brasil, a trajetória histórica, social, econômica e a política territorial, envolvendo os povos indígenas e os agricultores foram permeadas por um arcabouço de fatos, na questão de direitos e do jurídico brasileiro, em contextos complexos, os quais precisam ser abordados em profundidade. Dentre eles, destacamos a questão do direito à terra pois como registra Kaiser:

A questão dos direitos à terra foi o problema central dos direitos indígenas na Assembleia Nacional Constituinte de 1987/88, e ainda o é na realidade constitucional atual [...]. Por um lado, a terra não tem apenas significados especial para a sobrevivência física, mas também para a sobrevivência cultural dos índios. Elas têm relevância não somente para a garantia de existência no quadro da questão indígena. Ao contrário, existe uma ligação direta da questão da terra com a fé indígena e os conhecimentos indígenas. A concepção do território encontrase em uma ligação tão estreita com a história cultural das etnias, sua mitologia, as ligações familiares e o conjunto dos 
sistemas sociais, políticos e econômicos das populações indígenas, que a questão da terra recebe significado essencial para a garantia de sobrevivência dos índios como grupos populacionais etnicamente diferentes. (2010, p. 231-232).

Pode-se dizer que, no Rio Grande do Sul, desde as primeiras décadas do século XX, houve uma intensa política de demarcação das áreas indígenas. Contudo, apenas na década de 1990, efetivando-se o preceito constitucional, estabeleceu-se o processo de recuperação dos limites territoriais originalmente demarcados para as terras indígenas (KUJAWA, 2013, p. 82-83)

A concretização do direito indígena teve um alto custo social, provocando o deslocamento de um conjunto de agricultores que haviam recebido o título dessas terras, do governo do estado do Rio Grande do Sul, e agora precisavam buscar novas áreas para plantar e, na maioria dos casos, construírem um novo hábitat para suas famílias (KUJAWA, 2013, p. 82-83)

Ao ser concluído o processo de recuperação dos limites originais dos toldos indígenas, nas décadas de 1990 e 2000, iniciou-se uma nova etapa de demanda indígena, com a atuação da Funai, no pleito de ampliação ou constituição de novas áreas indígenas.

Em 2004, a Funai constituiu um grupo de trabalho para demarcar a terra indígena de Mato Preto (municípios de Getúlio Vargas e Erebango) e, dando sequência, também foram publicados os estudos demarcatórios do Passo do Forquilha (municípios de Sananduva e Cacique Doble) e Votouro (municípios de Faxinalzinho e Benjamin Constant), estando em fase de conclusão, os estudos da TI de Carreteiro (município de Água Santa), de Novo Xingu (municípios de Constantina e Novo Xingu), de Inhacorá (São Valério do Sul) e Mato Castelhano (Mato Castelhano) (KUJAWA, 2013, p. 84)

Quando o conflito pela terra não envolvia indígenas e nem comunidades quilombolas e, sim, latifúndio e pequenos agricultores (posseiros, sem-terra, arrendatários, dentre outros), havia uma definição ideológica e de representação mais definida e clara; se a luta social atual em questão não envolvesse territórios que contemplam pequenos agricultores (identificados como familiares), com titulação legal e secular e, sim, o latifúndio, possivelmente não haveria tensão e reconfiguração na esfera das mediações políticas, pois a propriedade privada da terra, aliada a fatores histórico-culturais dos sujeitos envolvidos, continua sendo central na sociedade contemporânea (KUJAWA; TEDESCO, 2017, p. 247).

É possível dizer que índios e agricultores são vítimas de um processo histórico que se corporifica na contemporaneidade, cujas razões abrangem a 
permanência na terra, onde o direito de um se sobrepõe ao direito do outro. Acrescente-se a fala proferida pelo antropólogo Eduardo Viveiros de Castro (2016), em aula pública, durante o ato Abril Indígena:

O Estado brasileiro e seus ideólogos sempre apostaram que os índios iriam desaparecer, e quanto mais rapidamente melhor; fizeram o possível e o impossível, o inominável e o abominável para tanto. Não que fosse preciso sempre exterminá-los fisicamente para isso - como sabemos, porém, o recurso ao genocídio continua amplamente em vigor no Brasil -- mas era sim preciso de qualquer jeito desindianizá-los, transformá-los em "trabalhadores nacionais". Cristianizá-los, "vesti-los" (como se alguém jamais tenha visto índios 'nus', esses mestres do adorno, da plumária, da pintura corporal), proibir-Ihes as línguas que falam ou falavam, os costumes que os definiam para si mesmos, submetê-los a um regime de trabalho, polícia e administração. Mas, acima de tudo, cortar a relação deles com a terra. Separar os índios (e todos os demais indígenas) de sua relação orgânica, política, social, vital com a terra e com suas comunidades que vivem da terra - essa separação sempre foi vista como 'condição necessária' para transformar o índio em cidadão. Em cidadão pobre, naturalmente. Porque sem pobres não há capitalismo, o capitalismo precisa de pobres, como precisou (e ainda precisa) de escravos. Transformar o índio em pobre. Para isso, foi e é preciso antes de mais nada separá-lo de sua terra, da terra que o 'constitui' como indígena.

Complementa-se que, no entendimento de Eduardo Viveiros de Castro, a terra é o corpo dos indígenas, assim como o indígena é parte da Terra, ou seja, existe uma estreita relação existencial entre ambos. Assim, privar o índio da Terra, é negar-lhe o direito ao próprio espírito.

De fato, os conflitos e a luta social, que se manifestam no Sul do Brasil, envolvendo indígenas e agricultores, devido a sua especificidade e intensidade, vêm contribuindo para que a sociedade em geral, assim como as entidades de representação e/ou mediação política, formem um juízo de valor, tomando partido e definindo posições, que em nada auxiliam os sujeitos envolvidos nos conflitos, os quais não se sobrepõem uns aos outros, em suas histórias, culturas e identidades. Daí a importância da mediação (KUJAWA; TEDESCO, 2017). Acrescente-se que, para se efetivar essa mediação, é preciso estabelecer uma discussão sobre essa questão, num amplo diálogo constituído de uma linguagem clara que atinja a capacidade de compreensão das partes envolvidas. 


\section{Conclusões}

A luta social que envolve os indígenas e os agricultores vem gerando tensões e conflitos, que perpassam os diretamente envolvidos na disputa pela terra, atingindo as entidades de representação dos sujeitos sociais, pois faz com que haja dúvidas, desconexão histórica e ausência de legitimidade, assim como alianças e lutas comuns entre entidades (KUJAWA; TEDESCO, 2017).

Esta constatação define a necessária reflexão sobre a mediação, impossível de se efetivar enquanto existirem percepções únicas, com soluções simplistas, para questões socioculturais legítimas e distintas, que assim precisam ser reconhecidas e representadas.

Nesse contexto, entende-se que qualquer mediação que não respeite, de maneira igualitária, o contexto histórico e social dos indígenas e dos agricultores, servirá apenas para fomentar o conflito na região norte do Rio Grande do Sul. Cabe afirmar que, historicamente, tanto os indígenas quanto os pequenos agricultores foram excluídos das políticas educacionais e econômicas no Brasil.

Os grupos envolvidos no conflito de terra - indígenas e não- indígenas precisam ter preservadas suas concepções e visões sobre o mundo. Portanto, toda e qualquer mediação, seja por meio de políticas públicas ou de entidades representativas, deverá atentar para as singularidades e as individualidades, ao desenvolver ações para atuar junto aos envolvidos. Urge construir um diálogo que possa traduzir, de fato, uma compreensão objetiva sobre as relações sociais, culturais e históricas que estão presentes no conflito da terra, o que transcende a dimensão econômica, a posse e a propriedade. E, nesse sentido, a Educação Ambiental Crítica pode servir como instrumento de denúncia e também de reivindicação em favor da garantia de vida desses povos que resistem, cotidianamente, na luta por seus direitos inalienáveis.

\section{Agradecimentos:}

Ao Conselho Nacional de Desenvolvimento Científico e Tecnológico $(\mathrm{CNPq})$, pelo apoio financeiro à pesquisa, através da Bolsa de Produtividade ao orientador do Darci Emiliano, professor Vilmar Alves Pereira.

\section{Referências}

ALMEIDA, S.P.D.; PICOLOTTO, E.L.; SPINELLI, L.M. Remoções e lutas dos Kaingang no norte do Rio Grande do Sul: a emancipação política Indígena compreendida a partir da teoria do reconhecimento. Mediações, Londrina, v. 22, n. 2, p. 72-98, jul./dez. 2017.

BELLO, E. Políticas de ações afirmativas no Brasil: uma análise acerca da viabilidade de um sistema de cotas sociais para ingresso nas universidades. Direito, Estado e Sociedade, v. 9, n. 26, p. 32-53, jan/jun, 2005.

revista brasileira educação ambiental 
COELHO, E.M.B. Ações afirmativas e povos indígenas: o princípio da diversidade em questão. Disponível em: $<$ http://www.periodicoseletronicos.ufma.br/index.php/rppublica/article/view/3802 >. Acesso em: 04 set. 2018.

EMILIANO, D. Revitalização dos saberes e práticas Kaingang sobre as plantas tradicionais como proposta de Educação Ambiental na terra indígena Ligeiro. Dissertação (Mestrado em Educação Ambiental) Programa de Pós-Graduação em Educação Ambiental da Universidade Federal do Rio Grande do Sul. Rio Grande: FURG, 2015.

FERREIRA, B. Vida e morte na concepção Kaingang, a partir da experiência concreta. In: MARKUS, C.; ALTMANN, L.; GIERUS, R. Saberes e espiritualidade indígenas. São Leopoldo: Oikus, 2014.

FREIRE, P. Pedagogia do Oprimido. 46. Ed. Rio de Janeiro: Paz e Terra, 2011.

KAYSER, $\mathrm{H}-\mathrm{E}$. Os direitos dos povos indígenas do Brasil: desenvolvimento histórico e estágio atual. Porto Alegre: Sergio Antonio Fabris Ed., 2010.

KUJAWA, H. A. Conflitos envolvendo indígenas e agricultores no Rio Grande do Sul: dilemas de políticas públicas contraditórias. Ciências Sociais Unisinos, São Leopoldo, v. 51, n. 1, jan/abr 2015.

KUJAWA, H.A.; TEDESCO, J.C. Mediações e representações em Conflito na luta pela terra entre Indígenas e agricultores no Norte do Rio Grande do Sul, Brasil. Revista GRIFOS, n. 42, 2017.

KUJAWA, H.A.; TEDESCO, J.C. Demarcações de terras indígenas no norte do Rio Grande do Sul e os atuais conflitos territoriais: uma trajetória histórica de tensões sociais. Tempos Históricos, v. 18, jul/dez, p. 67-88, 2014.

KUJAWA, H.A. Conflito entre a política indigenista e agricultores no norte do Rio Grande do Sul: uma localização da problemática. In: TEDESCO, João Carlos; KUJAWA, Henrique Aniceto. (Orgs.). Conflitos agrários no norte gaúcho: índios, negros e colonos. Passo Fundo: IMED: Porto Alegre: Letras\&Vida, 2013.

LOBATO, A.O.C.; BENEDETTI, E.J. Negros e índios: ações afirmativas e a realização da justiça social. JURIS, Rio Grande, n. 17, p. 75-91, 2012.

MOEHLECKE, S. Ação afirmativa: história e debates no Brasil. Cadernos de Pesquisa, n. 117, p. 197-217, novembro/ 2002.

PEREIRA, V.A; SCHIRMER, S.N. (Org.); JARDIM, D.B. (Org.). A política de ações afirmativas na FURG [recurso eletrônico]: um espaço de formação permanente. 1. ed. FURG: FURG, 2017. v. 1. 268p

PEREIRA, V.A. O que será o amanhã? Educação Ambiental na América Latina e Caribe, justiça Ambiental e COVID-19. Juiz de Fora, MG: Garcia, 2020. 
SILVA, A.L.F. et al. (Orgs.). Kanhgág AG Venh Kógan Kar AG Venhgrén: pintura e dança. Santo Ângelo, RS: Ediuri, 2009.

SOUZA FILHO, C.F.M. O renascer dos Povos Indígenas para o Direito. Curitiba: Juruá, 2010.

TEDESCO, J.C; CARINI, J.J. Conflitos agrários no norte gaúcho. Passo Fundo: IMED, 2010.

TEDESCO, J.C; KUJAWA, H.A. (Orgs.). Conflitos agrários no norte gaúcho: índios, negros e colonos. Passo Fundo: IMED: Porto Alegre: Letras\&Vida, 2013.

TEDESCO, J.C; SANDER, R. Madeireiros, comerciantes e granjeiros: lógicas e contradições no processo de desenvolvimento socioeconômico de Passo Fundo (1900-1960). Passo Fundo: UPF, 2002.

TEDESCO, J.C.; VANIN, J. Ações coletivas de luta pela terra e de defesa de modos de vida: índios, comunidades negras e colonos no norte do RS: um histórico de conflitos. In: TEDESCO, J. Carlos; KUJAWA, H.A. (Orgs.). Conflitos agrários no norte gaúcho: índios, negros e colonos. Passo Fundo: IMED: Porto Alegre: Letras\&Vida, 2013.

VEIGA, J. Mudanças no padrão de ocupação e produção nas terras indígenas kaingang. In: TEDESCO, João Carlos; CARINI, João Joel. Conflitos agrários no norte gaúcho. Passo Fundo: IMED, 2010.

VIVEIROS, E.C. Aula pública durante o ato Abril Indígena. Rio de Janeiro: Cinelândia, 2016. 